\section{Oral health status: relationship to nutrient and food intake among 80-year-old Japanese adults}

Iwasaki M, Taylor GW, Manz MC, Yoshihara A, Sato M, Muramatsu K, Watanabe R, Miyazaki H. Oral health status: relationship to nutrient and food intake among 80-year-old Japanese adults. Community Dent Oral Epidemiol 2014; 42: 441-450. (C) 2014 John Wiley \& Sons A/S. Published by John Wiley \& Sons Ltd

Abstract - Objectives: The aim of this cross-sectional study was to investigate the relationship of oral health status defined on the basis of presence of posterior occluding pairs (POPs) and adequacy of removable denture fit as determined by self-report to nutrient and food intake among older Japanese. Methods: The subjects were 353 Japanese aged 80 years in 2008 and were classified into four groups according to the number of POPs, defined as pairs of occluding natural, restored, or fixed prosthetic postcanine teeth (range: 0-8) and removable denture status. The groups were: (i) good dentition $(n=56 ; 8$ POPs and no removable prosthesis), (ii) well-fitting dentures $(n=158 ;<8$ POPs with self-reported good-fitting dentures), (iii) ill-fitting dentures ( $n=70 ;<8$ POPs with self-reported ill-fitting dentures), and (iv) compromised dentition ( $n=69 ;<8$ POPs and no removable prosthesis). Multivariable analysis of the differences in nutrient and food intake outcome variables which were collected via validated food frequency questionnaire among the four oral health status groups was conducted using general linear models. Results: Intake of multiple nutrients was significantly $(P<0.05)$ lower in the group with ill-fitting dentures or compromised dentition than in the good dentition group. Vegetable, fish, and shellfish consumption was significantly lower in the illfitting dentures or compromised dentition groups. No significant differences were seen in dietary intake between the well-fitting dentures and good dentition groups. Conclusions: Dietary intake was poorer in those with selfperceived ill-fitting dentures or fewer POPs than among those having all POPs. Regular dental care to maintain intact dentition, as well as dental treatment to replace missing teeth and ensure adequate denture fit and function, may be important to the diet intake and subsequent nutritional status of older Japanese.
Masanori Iwasaki ${ }^{1}$, George W. Taylor ${ }^{2}$, Michael C. Manz ${ }^{3,4}$, Akihiro Yoshihara ${ }^{5}$, Misuzu Sato ${ }^{1}$, Kanako Muramatsu ${ }^{6}$, Reiko Watanabe ${ }^{6}$ and Hideo Miyazaki ${ }^{1}$

${ }^{1}$ Division of Preventive Dentistry, Department of Oral Health Science, Graduate School of Medical and Dental Sciences, Niigata University, Niigata, Japan, ${ }^{2}$ Department of Preventive and Restorative Dental Sciences, University of California San Francisco, San Francisco, CA, USA, ${ }^{3}$ Department of Cariology, Restorative Sciences, and Endodontics, School of Dentistry, University of Michigan, Ann Arbor, MI, USA, ${ }^{4}$ Department of Cariology, Restorative Sciences \& ENDO (CRSE) 1011 N. University, Ann Arbor, MI, USA, ${ }^{5}$ Division of Oral Science for Health Promotion, Department of Oral Health and Welfare, Graduate School of Medical and Dental Sciences, Niigata University, Niigata, Japan, ${ }^{6}$ Department of Health and Nutrition, Faculty of Human Life Studies, University of Niigata Prefecture, Niigata, Japan

Key words: dietary intake; elderly; epidemiology; functional dentition; oral prosthesis

Masanori Iwasaki, Division of Preventive Dentistry, Department of Oral Health Science, Graduate School of Medical and Dental Sciences, Niigata University, 2-5274 Gakkocho-Dori, Chuo-Ku, Niigata 951-8514, Japan

Tel.: +8125227 2858

Fax: +81252270807

e-mail: masanori@dent.niigata-u.ac.jp

Submitted 19 June 2013; accepted 3 January 2014
Poor oral health can have a negative effect on nutrition. Tooth loss has been associated with impaired chewing ability and changes in food preference. Individuals who are either edentulous or have fewer natural teeth prefer soft, easily chew food that has low nutrient density (1-3). They therefore have lower intake of energy, protein, vitamins, minerals, and dietary fiber $(4,5)$. These consequences may ultimately lead to clinically important outcomes related to diet quality and nutritional deficiencies. As tooth loss is typically associated with older adults (6), growing awareness of the importance of oral health in the field of geriatric nutrition has been reported $(5,7)$.

There are indices of oral health status involving tooth loss that include considerations other than the number of teeth present. The location and function of the teeth is suggested to be more related to masticatory ability than merely the total number of teeth (8). Posterior teeth, which consist of four 
molars (excluding third molars) and four premolars in each arch for a total of 16 teeth or eight pairs, are primarily used for grinding and chewing food. These functional pairs of teeth are known as posterior occluding pairs (POPs) (8). Hildebrandt et al. (9) reported that fewer POPs, but not opposing anterior tooth pairs, were related to the perceived difficulty in chewing in a study of older adults (mean age: 70 years). Sahyoun et al. (7) reported that the number of POPs was more strongly associated with the nutritional status of individuals, as determined by dietary quality and serum levels of nutrients than the total number of teeth or the number of posterior teeth.

The presence and location of teeth is one measure of the oral health status; however, it has been suggested that it is difficult to assess oral function using the number of teeth without data on presence of prostheses (10). Removable dental prostheses, such as complete or partial dentures, can restore oral function to a certain degree (11). Studies have shown that not only the presence of dentures but also the quality of the denture fit was associated with nutrient and food intake and dietary variety. Well-fitting dentures can correct nutritional problems, whereas ill-fitting dentures cannot $(12,13)$.

Overall, accumulating evidence suggests that various oral health status indices are associated with nutrient and food intake and nutritional status. However, most of the studies, which focused on an index other than tooth loss (such as POPs or the quality of denture fit), did not include Asian populations. There are very limited data for people in Japan. Differing genetic backgrounds and lifestyles among populations may affect the association between oral health status and nutrition. Further study is needed to clarify this association in the Japanese, one of the fastest aging populations in the world. This study was therefore planned with the purpose of assessing whether oral health status, defined on the basis of the presence of POPs and self-reported adequacy of removable denture fit, was related to nutrient and food intake among 80-year-old Japanese subjects.

\section{Materials and methods}

\section{Study design and selection of study participants}

Cross-sectional data in June 2008 were derived from the Niigata study (Fig. 1). Briefly, the Niigata study is a community-based cohort study initiated in 1998 to evaluate the relationships between systemic health and oral health. In April 1998, all 4542 Niigata citizens aged 70 years (2099 men and 2443 women) were sent a written request to participate in the survey. The invitation was mailed again to nonrespondents 3 weeks later, and consequently, $81.4 \%(n=3695)$ responded positively to participate in the survey. Considering the availability of resources, examination appointments could be arranged for 600 individuals. The final study sample was randomly recruited from several areas of Niigata in order to have an approximately equal number of men $(n=306)$ and women $(n=294)$ (14). Participants had undergone annual follow-up examinations during 1999-2008. During 1998-2008, 241 of the 600 original participants were not available for the current study due to the following reasons: (i) 122 refused, (ii) 31 were hospitalized, (iii) eighty were deceased, and (iv) eight moved away from Niigata City. Therefore, 359 individuals who were 70 years old in 1998 and were 80 years old in 2008 were enrolled in the current study. They underwent routine follow-up examinations (dental examination, interview, and anthropometric evaluation) as well as dietary intake assessment. Six participants who did not submit complete data were excluded; therefore, the current study sample consisted of 353 participants aged 80 years in 2008.

This study was conducted according to the guidelines laid down in the Declaration of Helsinki, and all procedures involving human subjects were approved by the Ethics Committee of the Faculty of Dentistry, Niigata University. Written informed consent was obtained from all study participants.

\section{Dietary intake assessment}

Dietary habits during the preceding month were assessed with a brief-type self-administered diet history questionnaire (BDHQ) (15). The uses, reliability, and validity of this food frequency questionnaire were reported elsewhere (16, 17). Estimates of dietary intake for energy, nutrients, and food groups were calculated using an ad hoc computer algorithm for the BDHQ, which was based on the Standard Tables of Food Composition in Japan (18). Information on dietary supplement use was not available to the investigators, and therefore, nutrient intake from dietary supplements was not incorporated into the analysis.

\section{Dental examination}

The dental examination was conducted under sufficient illumination using artificial light by cali- 
April, 1998

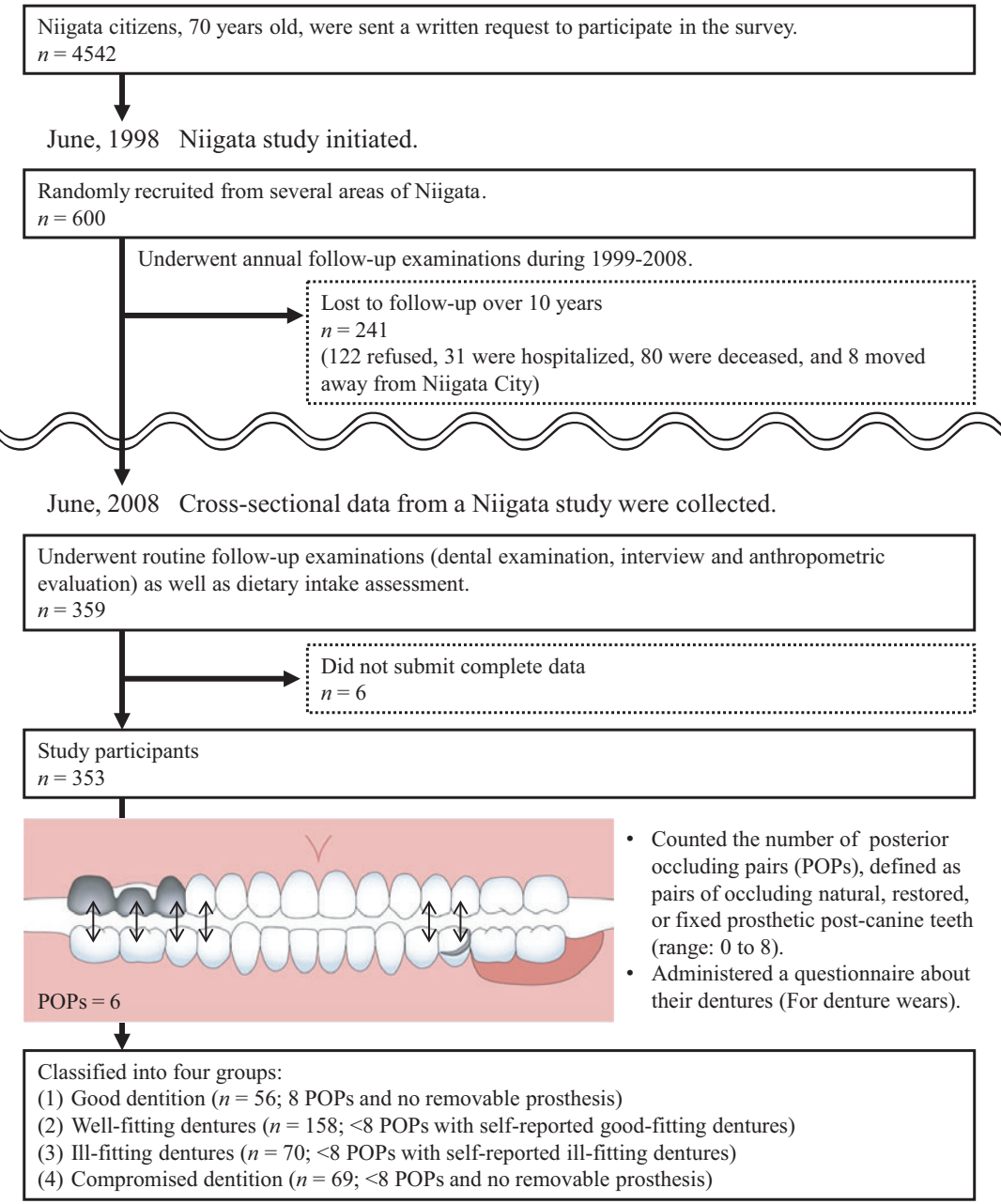

Fig. 1. Flow diagram of the study.

brated examiners as previously reported (5) (Fig. 1). The examinations included counting the number of POPs, which was defined as pairs of occluding natural, restored, or fixed prosthetic postcanine teeth (molars and premolars), excluding third molars (range: 0-8). No study participant had a dental implant. In addition to counting the number of POPs, participants who had an edentulous posterior zone (i.e., the number of POPs <8) were administered a questionnaire about removable dentures. The questionnaire consisted of questions about the use and fit of the dentures. The denture users were asked about the quality of their denture fit, 'In general, would you say the fit of your denture is excellent, good, poor, or very poor?' The answer was treated as a dichotomous variable with good fit encompassing the first two responses and ill fit, the last two responses.

\section{Description of main exposure variable}

Oral health status was defined by the number of POPs and removable denture status (Fig. 1). The four groups used to specify the main exposure variables for this study were: (i) good dentition ( $n=56 ; 8$ POPs and no removable prosthesis), (ii) well-fitting denture(s) $(n=158 ;<8$ POPs with selfreported well-fitting dentures), (iii) ill-fitting denture $(n=70 ;<8$ POPs with self-reported ill-fitting dentures), and (iv) compromised dentition ( $n=69$; $<8$ POPs and no removable prosthesis).

\section{Description of outcome variables}

Dietary intake of 13 specific nutrients and seven food groups were used for outcome variables. The 11 nutrients except for the carbohydrates and dietary fiber are listed in 'Dietary Reference Intakes (DRIs) for Japanese - 2010' (19) published by the Ministry of Health, Labour, and Welfare as nutrients 
to which the elderly (aged 70 years or older) should pay attention. Tests of normality using the Shapiro-Wilk statistic revealed that outcome variables were not normally distributed; therefore, a $\log _{10}$-transformed variable was used to achieve a more symmetric distribution. For outcome variables with a zero value, one-tenth of the lowest value above zero was added prior to log-transformation.

Dietary Reference Intakes includes the recommended intake levels for the nutrients for Japanese people aged 70 years and over [protein, $60 \mathrm{~g}$ /day for men, $50 \mathrm{~g} /$ day for women; carbohydrates, $50 \mathrm{E}$ $\%$ for men and women; n-3 polyunsaturated fatty acid (PUFA), $2.2 \mathrm{~g} /$ day for men, $1.8 \mathrm{~g} /$ day for women; sodium, $600 \mathrm{mg} /$ day for men and women; potassium, $2500 \mathrm{mg} /$ day for men, $2000 \mathrm{mg} /$ day for women; calcium, $700 \mathrm{mg} /$ day for men, $600 \mathrm{mg} /$ day for women; vitamin A, $800 \mu \mathrm{gRE} /$ day for men, $650 \mu \mathrm{gRE} /$ day for women; vitamin $\mathrm{D}$, $5.5 \mu \mathrm{g} /$ day for men and women; vitamin $\mathrm{E}$, $7.0 \mathrm{mg} /$ day for men, $6.5 \mathrm{mg} /$ day for women; vita$\min B_{6}, 1.4 \mathrm{mg} /$ day for men, $1.1 \mathrm{mg} /$ day for women; vitamin $B_{12}, 2.4 \mu \mathrm{g} /$ day for men and women; folate, $240 \mu \mathrm{g} /$ day for men and women; dietary fiber, $19 \mathrm{~g} /$ day for men, $17 \mathrm{~g} /$ day for women]. The number of the nutrients below the recommended intake levels (range: 0-13) was counted for each participant. Participants in the highest quartile (i.e., participants with $\geq 9$ nutrients below the recommended intake levels) were considered as those who were at risk of nutritional deficiencies. This dichotomous measure, nutritional deficiencies, was used for a secondary outcome variable.

\section{Statistical analyses}

Initially, analysis of variance for continuous variables and the chi-square test for categorical variables were used to test differences in the means and percentages of selected characteristics among different four study groups. Moreover, differences in these selected characteristics and additional characteristics related to the dentures between the well-fitting denture and ill-fitting denture groups were tested using independent $t$-tests for continuous variables and the chi-square test for categorical variables.

Multivariable analysis of the differences in nutrient intake and food group consumption outcome variables among four oral health status groups (referent category $=$ good dentition group) was conducted using general linear models to test the hypothesis that (1) the ill-fitting denture or compromised dentition groups had lower nutrient intake and food group consumption compared to the good dentition group, and (2) nutrient intake and food group consumption by the well-fitting denture group were not significantly different from the good dentition group. Multivariable models were adjusted for potential confounders: gender (categories: men or women), income (categories: annual household income $\geq$ or $<¥ 2000000 \mathrm{JP})$, education (categories: school attendance: $\geq$ or $<10$ years), smoking status (categories: never or current and previous smoker), alcohol use (categories: ethanol $<$ or $\geq 20 \mathrm{~g} /$ day), body mass index (BMI, continuous), and total energy intake (continuous). Effect modification was evaluated using interaction terms. Leastsquare means (LSMs) of nutrients and food groups were obtained across categories of oral health status.

As part of a sensitivity analysis, logistic regression analysis was performed including nutritional deficiencies as a secondary outcome measure.

The level of significance was set at $\alpha=0.05$. All calculations and statistical analyses were performed using the statistical software package STATA (version 12; Stata Corp., TX, USA).

\section{Results}

Table 1 shows study participants' characteristics by oral health status. Good dentition group had more intact teeth at 80 years old $(P<0.001)$ and fewer teeth lost during 10 years $(P<0.001)$. There were no significant differences in the demographic and socioeconomic, health status, behavioral characteristics, and total energy intake among the four groups.

Compared to the well-fitting denture group, illfitting denture group had fewer intact teeth $(P=0.004)$, more teeth lost during 10 years $(P=$ $0.022)$, shorter period of denture use $(P=0.048)$, and a lower percentage of those who visited dentist regularly $(P=0.024)$.

\section{Nutrient intake}

Table 2 shows the estimated LSMs and standard errors (SEs) of the dietary nutrients by the categories of oral health status. The antilog of $\log _{10}$ values for LSMs and SEs has been presented to provide interpretable results. The self-reported ill-fitting denture group had significantly $(P<0.05)$ lower 
Table 1. Selected characteristics of study participants by oral health status

\begin{tabular}{|c|c|c|c|c|c|c|c|}
\hline & \multirow[b]{2}{*}{$\begin{array}{l}\text { All participants } \\
n=353\end{array}$} & \multicolumn{4}{|l|}{ Oral health status } & \multirow[b]{2}{*}{$P^{*}$} & \multirow[b]{2}{*}{$P^{\dagger}$} \\
\hline & & $\begin{array}{l}\text { Good dentition } \\
n=56\end{array}$ & $\begin{array}{l}\text { Well-fitting } \\
\text { denture } \\
n=158\end{array}$ & $\begin{array}{l}\text { Ill-fitting } \\
\text { denture } \\
n=70\end{array}$ & $\begin{array}{l}\text { Compromised } \\
\text { dentition } \\
n=69\end{array}$ & & \\
\hline \multicolumn{8}{|c|}{ Dental conditions related to tooth loss } \\
\hline No. of intact teeth & $15.4 \pm 9.7$ & $27.6 \pm 1.9$ & $11.3 \pm 8.2$ & $8.1 \pm 6.5$ & $22.3 \pm 4.1$ & $<0.001$ & 0.004 \\
\hline $\begin{array}{l}\text { No. of teeth lost } \\
\text { during } 10 \text { years }\end{array}$ & $2.7 \pm 3.2$ & $0.5 \pm 0.9$ & $3.1 \pm 3.2$ & $4.3 \pm 4.2$ & $2.0 \pm 1.8$ & $<0.001$ & 0.022 \\
\hline $\begin{array}{l}\text { Duration of denture } \\
\text { use (years) }\end{array}$ & - & - & $15.2 \pm 11.8$ & $11.8 \pm 11.7$ & - & - & 0.048 \\
\hline \multicolumn{8}{|c|}{ Demographic and socioeconomic status } \\
\hline $\operatorname{Age}^{\mathrm{a}}$ & 80 & 80 & 80 & 80 & 80 & - & - \\
\hline \multicolumn{8}{|l|}{ Gender } \\
\hline Men & $174(49.3)$ & $28(50.0)$ & $75(47.5)$ & $34(48.6)$ & $37(53.6)$ & \multirow[t]{2}{*}{0.860} & \multirow[t]{2}{*}{0.878} \\
\hline Women & $179(50.7)$ & $28(50.0)$ & $83(52.5)$ & $36(51.4)$ & $32(46.4)$ & & \\
\hline \multicolumn{8}{|c|}{ Annual household income } \\
\hline$\geq ¥ 2000000 \mathrm{JP}$ & $304(86.1)$ & $50(89.3)$ & $132(83.5)$ & $61(87.1)$ & $61(88.4)$ & \multirow[t]{2}{*}{0.635} & \multirow[t]{2}{*}{0.487} \\
\hline$<¥ 2000000 \mathrm{JP}$ & 49 (13.9) & $6(10.7)$ & $26(16.5)$ & $9(12.9)$ & $8(11.6)$ & & \\
\hline \multicolumn{8}{|l|}{ Education level } \\
\hline $\begin{array}{l}\text { School } \\
\text { attendance } \\
\geq 10 \text { years }\end{array}$ & $208(58.9)$ & $32(57.1)$ & $92(58.2)$ & $39(55.7)$ & $45(65.2)$ & \multirow[t]{2}{*}{0.675} & \multirow[t]{2}{*}{0.723} \\
\hline $\begin{array}{l}\text { School } \\
\text { attendance } \\
<10 \text { years }\end{array}$ & $145(41.1)$ & $24(42.9)$ & $66(41.8)$ & $31(44.3)$ & $24(34.8)$ & & \\
\hline \multicolumn{8}{|c|}{ Health status and health behavior } \\
\hline BMI $\left(\mathrm{kg} / \mathrm{m}^{2}\right)$ & $22.0 \pm 3.1$ & $21.9 \pm 2.9$ & $22.3 \pm 3.2$ & $21.7 \pm 3.1$ & $21.9 \pm 2.8$ & 0.566 & 0.191 \\
\hline \multicolumn{8}{|l|}{ Regular dental visits } \\
\hline Yes & 189 (53.5) & $33(58.9)$ & $91(57.6)$ & $29(41.4)$ & $36(52.2)$ & \multirow[t]{2}{*}{0.118} & \multirow[t]{2}{*}{0.024} \\
\hline No & $164(46.5)$ & $23(41.1)$ & $67(42.4)$ & $41(58.6)$ & $33(47.8)$ & & \\
\hline \multicolumn{8}{|c|}{ Dental visits with denture problems in past year } \\
\hline Yes & - & - & $35(37.6)$ & $24(53.3)$ & - & & \multirow[t]{2}{*}{0.081} \\
\hline No & - & - & $58(62.4)$ & $21(46.7)$ & - & & \\
\hline \multicolumn{8}{|l|}{ Smoking status } \\
\hline Never smoker & $225(63.7)$ & $38(67.9)$ & $99(62.7)$ & $45(64.3)$ & $43(62.3)$ & \multirow[t]{2}{*}{0.906} & \multirow[t]{2}{*}{0.814} \\
\hline $\begin{array}{l}\text { Current \& } \\
\text { previous smoker }\end{array}$ & $128(36.3)$ & $18(32.1)$ & $59(37.3)$ & $25(35.7)$ & $26(37.7)$ & & \\
\hline \multicolumn{8}{|c|}{ Alcohol consumption } \\
\hline Ethanol <20 g/day & $309(87.5)$ & $48(85.7)$ & $136(86.1)$ & $63(90.0)$ & $62(89.9)$ & \multirow[t]{2}{*}{0.751} & \multirow[t]{2}{*}{0.412} \\
\hline Ethanol $\geq 20 \mathrm{~g} /$ day & $44(12.5)$ & $8(14.3)$ & $22(13.9)$ & $7(10.0)$ & $7(10.1)$ & & \\
\hline \multicolumn{8}{|l|}{ Total energy intake } \\
\hline Energy intake (kcal) & $2077 \pm 653$ & $2217 \pm 730$ & $2104 \pm 629$ & $1964 \pm 612$ & $2016 \pm 669$ & 0.135 & 0.117 \\
\hline
\end{tabular}

Continuous variables are expressed as the mean \pm standard deviation; categorical variables, as $n$ (percentage).

Good dentition group = eight posterior occluding pairs and no removable prosthesis; well-fitting denture group $=<8$ posterior occluding pairs with self-reported well-fitting dentures; ill-fitting denture group $=<8$ posterior occluding pairs with self-reported ill-fitting dentures; compromised dentition group $=<8$ posterior occluding pairs and no removable prosthesis.

Text in boldface highlights statistically significant findings $(P<0.05)$.

${ }^{a}$ All participants were 80 years of age.

* $P$ value for the comparison of selected characteristics among four different study groups.

${ }^{\dagger} P$ value for the comparison of selected characteristics between the well-fitting denture and ill-fitting denture groups.

intake of protein, n-3 PUFA, potassium, calcium, vitamin $D$, vitamin $E$, vitamin $B_{6}$, and vitamin $B_{12}$ than the good dentition group after adjusting for confounders. Mean dietary intake of protein, n-3 PUFA, potassium, calcium, vitamin A, vitamin D, vitamin $\mathrm{E}$, vitamin $\mathrm{B}_{6}$, folate, and dietary fiber in the compromised dentition group was also signifi- cantly $(P<0.05)$ lower than in the good dentition group, adjusting for confounding variables (Table 2). No significant differences were seen in nutrient intake between the well-fitting denture and the good dentition groups. There were no interactions of the oral health status with covariates. 
Table 2. Associations between oral health status and nutrient intake $\mathrm{a}^{\mathrm{a}, \mathrm{b}, \mathrm{c}}$

\begin{tabular}{|c|c|c|c|c|c|c|c|c|c|c|c|}
\hline \multirow[b]{4}{*}{ Dietary variables } & \multicolumn{11}{|c|}{ Oral health status } \\
\hline & \multirow{2}{*}{\multicolumn{2}{|c|}{$\begin{array}{l}\text { Good dentition } \\
\text { (Referent) } \\
n=56\end{array}$}} & \multirow{2}{*}{\multicolumn{3}{|c|}{$\begin{array}{l}\text { Well-fitting denture } \\
n=158 \\
\end{array}$}} & \multirow{2}{*}{\multicolumn{3}{|c|}{$\begin{array}{l}\text { Ill-fitting denture } \\
n=70 \\
\end{array}$}} & \multirow{2}{*}{\multicolumn{3}{|c|}{$\begin{array}{l}\begin{array}{l}\text { Compromised } \\
\text { dentition }\end{array} \\
n=69 \\
\end{array}$}} \\
\hline & & & & & & & & & & & \\
\hline & LSM & SE & LSM & SE & $P^{*}$ & LSM & SE & $P^{*}$ & LSM & SE & $P^{*}$ \\
\hline Protein (g/day) & 79 & 3 & 77 & 2 & 0.316 & 71 & 2 & 0.005 & 72 & 2 & 0.006 \\
\hline Carbohydrates (g/day) & 239 & 6 & 242 & 4 & 0.689 & 250 & 6 & 0.123 & 249 & 6 & 0.161 \\
\hline \multicolumn{12}{|l|}{ Fat } \\
\hline \multicolumn{12}{|l|}{ Minerals } \\
\hline Sodium (mg/day) & 4949 & 155 & 4949 & 112 & 0.998 & 4703 & 139 & 0.147 & 4717 & 142 & 0.173 \\
\hline Potassium (mg/day) & 3341 & 127 & 3213 & 88 & 0.286 & 3033 & 109 & 0.023 & 2937 & 107 & 0.003 \\
\hline Calcium (mg/day) & 685 & 31 & 648 & 21 & 0.195 & 578 & 24 & 0.001 & 612 & 26 & 0.026 \\
\hline \multicolumn{12}{|l|}{ Vitamins } \\
\hline Vitamin A ( $\mu \mathrm{g} /$ day RE) & 861 & 56 & 828 & 39 & 0.540 & 769 & 47 & 0.121 & 736 & 46 & 0.033 \\
\hline Vitamin D ( $\mu \mathrm{g} /$ day) & 19.3 & 1.9 & 17.7 & 1.3 & 0.382 & 14.5 & 1.3 & 0.010 & 14.8 & 1.4 & 0.017 \\
\hline Vitamin E ( $\mu \mathrm{g} /$ day $)$ & 9.8 & 0.4 & 9.5 & 0.3 & 0.519 & 8.9 & 0.3 & 0.024 & 8.6 & 0.3 & 0.002 \\
\hline Vitamin $\mathrm{B}_{6}(\mathrm{mg} /$ day $)$ & 1.66 & 0.06 & 1.59 & 0.04 & 0.221 & 1.52 & 0.05 & 0.035 & 1.44 & 0.05 & 0.001 \\
\hline Vitamin $B_{12}(\mu \mathrm{g} /$ day $)$ & 12.0 & 1.0 & 11.3 & 0.7 & 0.509 & 9.5 & 0.8 & 0.018 & 9.9 & 0.8 & 0.050 \\
\hline Folate $(\mu \mathrm{g} /$ day $)$ & 461 & 22 & 445 & 15 & 0.441 & 416 & 18 & 0.054 & 409 & 18 & 0.024 \\
\hline Dietary fiber (g/day) & 15.7 & 0.7 & 15.3 & 0.5 & 0.549 & 14.7 & 0.6 & 0.175 & 14.1 & 0.6 & 0.031 \\
\hline
\end{tabular}

LSM, least-square mean; SE, standard error; RE, retinol; PUFA, polyunsaturated fatty acid.

Good dentition group = eight posterior occluding pairs and no removable prosthesis; well-fitting denture group $=<8$ posterior occluding pairs with self-reported well-fitting dentures; ill-fitting denture group $=<8$ posterior occluding pairs with self-reported ill-fitting dentures; compromised dentition group $=<8$ posterior occluding pairs and no removable prosthesis.

Text in boldface highlights statistically significant findings $(P<0.05)$.

aAdjusted for gender, income, education, smoking status, alcohol use, body mass index, and total calorie intake.

${ }^{\mathrm{b}}$ The dietary variables were $\log _{10}$-transformed prior to analyses.

${ }^{\mathrm{c}}$ The antilog of $\log _{10}$ values for LSM and SE has been presented to provide meaningful results.

*Comparison to referent category.

\section{Food group intake}

The antilog of $\log _{10}$ values for estimated LSMs and SEs of food group consumption among four oral health status categories is presented in Table 3. Consumption of vegetables, fish, and shellfish by the ill-fitting denture group or compromised dentition group was significantly $(P<0.05)$ lower than that by the good dentition group, after controlling for confounders. There were no significant differences in food group consumption between well-fitting denture and good dentition groups.

\section{Recommended nutrient intake level}

The results of the logistic regression model are displayed in Table 4, with nutritional deficiencies, which is defined using the recommended intake levels, as the dichotomous outcome variable. The unadjusted model (model 1) showed a significant association of oral health status with nutritional deficiencies. The odds ratio (OR) of nutritional deficiencies was 3.27 [95\% confidence interval (CI), 1.12-9.53] for the ill-fitting denture group and 3.08 (95\% CI, 1.05-9.02) for the compromised dentition group, compared to the good dentition group. In model 2 (multivariable adjusted model), this association was attenuated and no longer statistically significant. Nevertheless, there was a tendency for the ill-fitting denture and compromised dentition groups to have greater ORs for nutritional deficiencies [adjusted OR (95\% $\mathrm{CI})=2.84(0.95-8.50)$ for the ill-fitting denture group and adjusted OR $(95 \% \mathrm{CI})=2.61 \quad(0.87-$ 7.88) for the compromised dentition group, respectively].

\section{Discussion}

Intake of multiple nutrients was significantly lower in participants with self-perceived ill-fitting dentures or fewer POPs. This seems to be partly attributable to lower vegetable intake by the ill-fitting denture group or compromised dentition group. Vegetables are perceived as difficult to chew and are one of the primary sources of many vitamins, 
Table 3. Associations between oral health status and food consumption ${ }^{\text {a }}$

\begin{tabular}{|c|c|c|c|c|c|c|c|c|c|c|c|}
\hline \multirow[b]{4}{*}{ Dietary variables } & \multicolumn{11}{|c|}{ Oral health status } \\
\hline & \multirow{2}{*}{\multicolumn{2}{|c|}{$\begin{array}{l}\text { Good } \\
\text { dentition } \\
\text { (Referent) } \\
n=56\end{array}$}} & \multirow{2}{*}{\multicolumn{3}{|c|}{$\begin{array}{l}\text { Well-fitting denture } \\
n=158\end{array}$}} & \multirow{2}{*}{\multicolumn{3}{|c|}{$\begin{array}{l}\text { Ill-fitting denture } \\
n=70\end{array}$}} & \multirow{2}{*}{\multicolumn{3}{|c|}{$\begin{array}{l}\text { Compromised } \\
\text { dentition } \\
n=69\end{array}$}} \\
\hline & & & & & & & & & & & \\
\hline & LSM & SE & LSM & SE & $P^{*}$ & LSM & SE & $P^{*}$ & LSM & SE & $P^{*}$ \\
\hline Rice (g/day) & 207 & 20 & 209 & 15 & 0.926 & 225 & 21 & 0.440 & 229 & 21 & 0.352 \\
\hline Nuts and pulses (g/day) & 69 & 11 & 70 & 15 & 0.946 & 59 & 11 & 0.131 & 65 & 11 & 0.514 \\
\hline Fruits (g/day) & 94 & 15 & 90 & 10 & 0.735 & 74 & 11 & 0.168 & 74 & 11 & 0.163 \\
\hline Vegetables (g/day) & 332 & 25 & 309 & 17 & 0.330 & 275 & 19 & 0.025 & 271 & 19 & 0.016 \\
\hline Fish and shellfish (g/day) & 111 & 11 & 102 & 7 & 0.384 & 81 & 8 & 0.007 & 85 & 8 & 0.021 \\
\hline Meat (g/day) & 38 & 7 & 37 & 5 & 0.968 & 34 & 6 & 0.617 & 33 & 6 & 0.527 \\
\hline Confectionery (g/day) & 22 & 5 & 25 & 4 & 0.607 & 33 & 7 & 0.104 & 35 & 8 & 0.082 \\
\hline
\end{tabular}

LSM, least-square mean; SE, standard error.

Good dentition group = eight posterior occluding pairs and no removable prosthesis; well-fitting denture group $=<8$ posterior occluding pairs with self-reported well-fitting dentures; ill-fitting denture group $=<8$ posterior occluding pairs with self-reported ill-fitting dentures; compromised dentition group $=<8$ posterior occluding pairs and no removable prosthesis.

Text in boldface highlights statistically significant findings $(P<0.05)$.

${ }^{a}$ Adjusted for gender, income, education, smoking status, alcohol use, body mass index, and total calorie intake.

${ }^{*}$ Comparison to referent category.

Table 4. Associations between oral health status and recommended nutrient intake level

\begin{tabular}{lll}
\hline $\begin{array}{l}\text { Outcome: nutritional } \\
\text { deficiencies }\end{array}$ & $\begin{array}{l}\text { Model 1 } \\
\text { (Oral health } \\
\text { status only) }\end{array}$ & $\begin{array}{l}\text { Model 2 } \\
\text { (Model 1 + } \\
\text { Potential } \\
\text { confounders) }\end{array}$ \\
\hline $\begin{array}{l}\text { Oral health status } \\
\text { Good dentition } \\
\begin{array}{l}\text { Referent) } \\
\text { Well-fitting } \\
\text { denture }\end{array}\end{array}$ & 1.00 & 1.00 \\
$\begin{array}{c}\text { Ill-fitting } \\
\text { denture }\end{array}$ & $1.48(0.53-4.15)$ & $1.39(0.48-3.98)$ \\
$\begin{array}{l}\text { Compromised } \\
\text { dentition }\end{array}$ & $3.08(1.05-9.02)^{*}$ & $2.61(0.87-7.88)$ \\
\hline
\end{tabular}

Nutritional deficiencies $=$ a dichotomous variable for participants with $\geq 9$ nutrients below the recommended intake levels versus those with $<9$ nutrients below the recommended intake levels; Model $1=$ unadjusted/univariate model; Model 2 = model 1 and gender, income, education, smoking status, alcohol use, BMI, and total calorie intake.

${ }^{*} P<0.05$

minerals, and fiber. In addition, participants with self-perceived ill-fitting dentures or fewer POPs consumed significantly less fish and shellfish. These results are mirrored in the lower intake of n-3 PUFA, which are mainly found in fish and seafood. Not all but some kinds of fish and shellfish are perceived as difficult to chew (20). In contrast, dietary intake by individuals with well-fitting den- tures was not significantly different from individuals with all POPs.

Our findings suggest that oral health status (based on POPs and denture fit) can influence individual's food choice and their nutrient intake. However, it is important to note that there are several factors other than oral health status that influence food choice, such as food preferences, dietary habits, nutritional knowledge, cooking skills, and available food sources as well as psychosocial factors $(7,21)$. The current study does not include data to address such factors; consequently, we could not include them in the analyses.

The recommended intake levels included in DRIs are quantities that are sufficient to maintain a satisfactory nutritional status of a particular gender and age group (22). Although the association was not statistically significant, the ill-fitting denture and compromised dentition groups tended to have greater ORs for nutritional deficiencies. One explanation for the lack of statistical significance may be sample size limitations. Future work with larger, more diversified samples and more complete information would be necessary to substantiate our findings.

There were no significant differences in the carbohydrates intake among the four groups. Carbohydrate intake accounted for $51.7 \%$ of the total energy intake in this study population. Forty six percent of total carbohydrates came from cereals 
including rice, and $18 \%$ were from confectionery. Actually, rice and confectionery were the first and second food groups as energy sources and accounted for $20 \%$ and $13 \%$ of the total energy intake, respectively. Rice intake was not associated with the oral health status. Participants with fewer POPs consumed marginally nonsignificantly higher confectionery $(P=0.082)$. These findings could partly explain the lack of difference in total energy intake and lack of difference in BMI among the four groups. Individuals with poor oral health may prefer high-calorie, low-nutrient dense foods that are easy to chew. Similar findings have been reported in previous reports (1-3).

Associations of nutrient and food intake and nutritional status with systemic health have been reported. Protein deficiency increases susceptibility to a variety of pathogens (23). Inadequate dietary calcium and vitamin D intake is associated with reduced bone mass and osteoporosis (24). Increased intake of antioxidant vitamins such as vitamins $\mathrm{A}$ and $\mathrm{E}$ reduces the incidence rates of vascular disease, cancer, and other adverse outcomes $(25,26)$. Folate and B vitamins are important regulators in homocysteine metabolism. It is demonstrated that lowering of homocysteine with folic acid and vitamins $B_{6}$ and $B_{12}$ reduced the risk of stroke (27). The traditional Japanese diet is characterized by high consumption of fish (28). An inverse association was found between fish consumption and the development of cardiovascular disease (29). There is also a possible association between specific nutrients and oral health. We previously demonstrated an inverse, independent relationship of dietary antioxidant vitamin intake as well as n-3 PUFA intake to the progression of periodontal disease in older Japanese $(30,31)$. Thus, inadequate dietary intake associated with poor dentition, tooth loss, and ill-fitting dentures can lead to further oral and systemic health problems.

Regular dental maintenance has been reported to be associated with lower risk of tooth loss (32) and long-term survival of dental prostheses (33). In the current study, the good dentition group had fewer teeth lost during 10 years. Additionally, the well-fitting denture group had more intact teeth, fewer teeth lost during 10 years, and a higher percentage of those who visited dentist regularly, compared to the ill-fitting denture group. Therefore, regular dental care to maintain an intact dentition, as well as dental treatment to replace missing teeth and ensure adequate denture fit and function, may be important to the nutritional status of older Japanese and, ultimately, to their overall health.

The well-fitting denture group had a longer period of denture use than the ill-fitting denture group. It is reported that elderly experienced denture wearers are more likely to accept limitations of denture wearing than their younger counterparts and that older adults with a long history of denture wearing accept edentulousness as part of the aging process (34). The experiences of the denture use are associated with the attitudes toward edentulousness and acceptance of the dentures and may influence dietary intake among the elderly.

The strength of this study is that the data are derived from a homogenous group of older Japanese restricted to the age of 80 years, which eliminated the influences of variations in age and race on our results, and directly addresses a Japanese population. On the other hand, there is a potential risk that our final sample analyzed may not be representative of the originally sampled cohort. Only 359 participants of the 600 original cohort of the Niigata study underwent examinations in 2008. Selected characteristics in 1998 were compared between the 359 participants and 241 individuals who dropped out. The 241 withdrawals had fewer remaining teeth, and a higher percentage of those were current smokers [241 individuals who dropped out versus 359 participants, $16.4 \pm 9.4$ (mean \pm standard deviation) versus $18.1 \pm 9.2$, $P=0.032$, for the number of teeth and $23.5 \%$ versus $16.3 \%, P=0.031$, for the percentage of current smokers, respectively]. In this context, the present sample may be healthier than the general population; therefore, the results based on this single study should be interpreted with some caution, because this selection bias may lead to over- or underestimation of the true association. There are several other limitations to the present study. First, our study had a cross-sectional design, which prevented us from assessing a temporal relationship and establishing causality. Second, dietary habits are subject to seasonal variation (35). In the current study, dietary habits during May were assessed with a validated food frequency questionnaire, BDHQ. Although BDHQ showed reasonable validity for food intake estimations in each of the four seasons (17), the effect of seasonal dietary intake variation on the observed associations of oral health status with nutrient and food intake was unclear. Third, information on participants' serum albumin levels was not available to the investigators, and therefore, we were unable to fully assess 
participants' nutritional status. Fourth, swallowing difficulties can influence the nutritional outcomes in older adults (36); however, information on participants' swallowing function was not collected; hence, this potentially important factor could not be assessed in the analyses. Fifth, information on nutritional supplement use was not available; therefore, it was not possible to assess with complete accuracy the amount of dietary nutrients, leading to over- or underestimation of the observed association. In the National Health and Nutrition Survey Japan 2008 of people aged 70 years or over $(n=1877)$ (37), the percentage of individuals taking any supplement was of $16.9 \%$ $(n=272)$. Sixth, because there is no summary measure of the overall quality of an individual's diet in Japan, such as the Healthy Eating Index in the United States., we could not examine the association between the oral health status and overall diet quality. Finally, in this report, denture status was based on the participant's self-assessment. No clinical measurements were taken; therefore, an individual's oral health status may differ from the evaluation of their oral health status by a dental healthcare professional. Sahyoun et al. (13) used both self-assessed and examiner-assessed measures of denture fit. They found no consistent association between denture fit determined by a dental examination and dietary quality or nutrient intake and concluded that self-perceived denture fit appears to have a greater impact on eating habits and nutritional status than a dentist's evaluation of fit. The results of the present study indicate that self-perceived denture fit is related to dietary intake among older Japanese. Administering a questionnaire to denture wearers about their perceptions of denture fit may be useful to identify people at risk of experiencing low nutrient intake.

In summary, poor oral health status (based on POPs and denture fit) was associated with decreased food consumption and lower nutrient intake among 80-year-old Japanese subjects. This observed association provides evidence of the relationship of oral health with nutrition and further with systemic health in older people.

\section{Acknowledgments}

This work was supported by Grants-in-Aid from the Ministry of Health and Welfare of Japan (H10-Iryo-001, H13-Iryo-001, and H16-Iryo-020) and a Grant for the Promotion of Niigata University Research Projects (24C058).

\section{Conflict of interest}

The authors have no conflict of interest to report.

\section{References}

1. Joshipura KJ, Willett WC, Douglass CW. The impact of edentulousness on food and nutrient intake. J Am Dent Assoc 1996;127:459-67.

2. Krall E, Hayes C, Garcia R. How dentition status and masticatory function affect nutrient intake. J Am Dent Assoc 1998;129:1261-9.

3. Sheiham A, Steele JG, Marcenes W, Lowe C, Finch S, Bates CJ et al. The relationship among dental status, nutrient intake, and nutritional status in older people. J Dent Res 2001;80:408-13.

4. Sheiham A, Steele J. Does the condition of the mouth and teeth affect the ability to eat certain foods, nutrient and dietary intake and nutritional status amongst older people? Public Health Nutr 2001;4:797-803.

5. Yoshihara A, Watanabe R, Nishimuta M, Hanada N, Miyazaki $\mathrm{H}$. The relationship between dietary intake and the number of teeth in elderly Japanese subjects. Gerodontology 2005;22:211-8.

6. Eklund SA, Burt BA. Risk factors for total tooth loss in the united states; longitudinal analysis of national data. J Public Health Dent 1994;54:5-14.

7. Sahyoun NR, Lin CL, Krall E. Nutritional status of the older adult is associated with dentition status. J Am Diet Assoc 2003;103:61-6.

8. Moriya S, Tei K, Muramatsu T, Murata A, Muramatsu M, Harada E et al. Factors associated with selfassessed masticatory ability among communitydwelling elderly Japanese. Community Dent Health 2012;29:39-44.

9. Hildebrandt GH, Dominguez BL, Schork MA, Loesche WJ. Functional units, chewing, swallowing, and food avoidance among the elderly. J Prosthet Dent 1997;77:588-95.

10. Gift HC. Oral health outcomes research: challenges and opportunities. In: Slade GD, editor. Measuring oral health and quality of life. Chapel Hill, NC: Department of Dental Ecology, University of North Carolina, 1997; 25-46.

11. Gunne HS. The effect of removable partial dentures on mastication and dietary intake. Acta Odontol Scand 1985;43:269-78.

12. Marshall TA, Warren JJ, Hand JS, Xie XJ, Stumbo PJ. Oral health, nutrient intake and dietary quality in the very old. J Am Dent Assoc 2002;133:1369-79.

13. Sahyoun NR, Krall E. Low dietary quality among older adults with self-perceived ill-fitting dentures. J Am Diet Assoc 2003;103:1494-9.

14. Hirotomi T, Yoshihara A, Ogawa H, Miyazaki H. Tooth-related risk factors for tooth loss in community-dwelling elderly people. Community Dent Oral Epidemiol 2012;40:154-63.

15. Sasaki S. Development and evaluation of dietary assessment methods using biomarkers and diet history questionnaires for individuals (in Japanese). In: Tanaka H, editor. Research for evaluation methods of nutrition and dietary lifestyle programs held on 
healthy Japan 21. Summary Report. Tokyo: The Ministry of Health, Welfare, and Labour, 2004; 10-44.

16. Kobayashi S, Honda S, Murakami K, Sasaki S, Okubo $\mathrm{H}$, Hirota $\mathrm{N}$ et al. Both comprehensive and brief self-administered diet history questionnaires satisfactorily rank nutrient intakes in Japanese adults. J Epidemiol 2012;22:151-9.

17. Kobayashi S, Murakami K, Sasaki S, Okubo H, Hirota N, Notsu A et al. Comparison of relative validity of food group intakes estimated by comprehensive and brief-type self-administered diet history questionnaires against $16 \mathrm{~d}$ dietary records in Japanese adults. Public Health Nutr 2011;14:1200-11.

18. The Science and Technology Agency. Standard tables of food composition in Japan, 5th revised edn (in Japanese). Tokyo: National Printing Bureau; 2005.

19. The Ministry of Health, Labour, and Welfare. Dietary Reference Intakes for Japanese - 2010; available at: http:/ / www.mhlw.go.jp/shingi/2009/05/dl/s05 29-4at.pdf [last accessed 26 May 2013].

20. Murakami K, Sasaki S, Takahashi Y, Uenishi K, Yamasaki M, Hayabuchi $\mathrm{H}$ et al. Hardness (difficulty of chewing) of the habitual diet in relation to body mass index and waist circumference in free-living Japanese women aged 18-22 y. Am J Clin Nutr 2007;86:206-13.

21. Rodrigues HL Jr, Scelza MF, Boaventura GT, Custodio SM, Moreira EA, Oliveira Dde L. Relation between oral health and nutritional condition in the elderly. J Appl Oral Sci 2012;20:38-44.

22. Sasaki S. Dietary reference intakes (dris) in Japan. Asia Pac J Clin Nutr 2008;17(Suppl 2):420-44.

23. Scrimshaw NS, SanGiovanni JP. Synergism of nutrition, infection, and immunity: an overview. Am J Clin Nutr 1997;66:464S-77S.

24. Gennari C. Calcium and vitamin d nutrition and bone disease of the elderly. Public Health Nutr 2001;4:547-59.

25. Fulan H, Changxing J, Baina WY, Wencui Z, Chunqing L, Fan W et al. Retinol, vitamins a, c, and e and breast cancer risk: a meta-analysis and meta-regression. Cancer Causes Control 2011;22:1383-96.

26. Knekt P, Ritz J, Pereira MA, O’Reilly EJ, Augustsson $\mathrm{K}$, Fraser GE et al. Antioxidant vitamins and coronary heart disease risk: a pooled analysis of 9 cohorts. Am J Clin Nutr 2004;80:1508-20.
27. Saposnik G, Ray JG, Sheridan P, McQueen M, Lonn E. Homocysteine-lowering therapy and stroke risk, severity, and disability: additional findings from the hope 2 trial. Stroke 2009;40:1365-72.

28. Shimazu T, Kuriyama S, Hozawa A, Ohmori K, Sato $\mathrm{Y}, \mathrm{Nakaya} \mathrm{N}$ et al. Dietary patterns and cardiovascular disease mortality in Japan: a prospective cohort study. Int J Epidemiol 2007;36:600-9.

29. Whelton SP, He J, Whelton PK, Muntner P. Metaanalysis of observational studies on fish intake and coronary heart disease. Am J Cardiol 2004;93:111923.

30. Iwasaki M, Yoshihara A, Moynihan P, Watanabe R, Taylor GW, Miyazaki H. Longitudinal relationship between dietary omega-3 fatty acids and periodontal disease. Nutrition 2010;26:1105-9.

31. Iwasaki M, Moynihan P, Manz MC, Taylor GW, Yoshihara A, Muramatsu K et al. Dietary antioxidants and periodontal disease in community-based older Japanese: a 2-year follow-up study. Public Health Nutr 2012;16:330-8.

32. Costa FO, Lages EJ, Cota LO, Lorentz TC, Soares RV, Cortelli JR. Tooth loss in individuals under periodontal maintenance therapy: 5-year prospective study. J Periodontal Res 2014;49:121-8.

33. Ikai H, Kanno T, Kimura K, Sasaki K. A retrospective study of fixed dental prostheses without regular maintenance. J Prosthodont Res 2010;54:173-8.

34. Allen PF, McMillan AS. A review of the functional and psychosocial outcomes of edentulousness treated with complete replacement dentures. J Can Dent Assoc 2003;69:662.

35. Ogawa K, Tsubono Y, Nishino Y, Watanabe Y, Ohkubo $\mathrm{T}$, Watanabe $\mathrm{T}$ et al. Inter- and intra-individual variation of food and nutrient consumption in a rural Japanese population. Eur J Clin Nutr 1999;53:781-5.

36. Mann $T$, Heuberger $R$, Wong $H$. The association between chewing and swallowing difficulties and nutritional status in older adults. Aust Dent J 2013;58:200-6.

37. The Ministry of Health, Labour, and Welfare. National Health and Nutrition Survey; available at: http://www.mhlw.go.jp/bunya/kenkou/eiyou/dl/ h20-houkoku-01a.pdf [accessed 26 May 2013]. 